omeprazole and other $\mathrm{H}+/ \mathrm{K}+-\mathrm{ATPase}$ inhibitors against Helicobacter pylori. Rev ESP Enf Digest 1990; 78: P256.

10 Suerbaum S, Leying $\mathrm{H}$, Klemm K, Opferkuch W. Antibacterial activity of pantoprazole and omeprazole against Helicobacter pylori. Eur J Clin Microbiol Infect Dis 1991; 10: 92-93.
11 Vaira D, Malfertheiner P, Megraud F, et al. Diagnosis of Helicobacter infection with a new non-invasive antigen-based assay. HpSA European study group. Lancet 1999; 354: 30-33.

DOI: $10.1183 / 09031936.00033907$

\title{
Origin of the term XDR-TB
}

\section{To the Editors:}

MigLIORI et al. [1] have written a commendable editorial about the challenges to science presented by the emergence of extensively drug-resistant tuberculosis (XDR-TB) as a named entity. We wish to clarify the origin and development of the term "XDR-TB".

As noted by MigLIORI et al. [1], resistance to second-line drugs is not a new phenomenon. Despite years of anecdotal reports about "super bugs" and TB strains (predominantly in the former Soviet Union and Asia) with resistance to six, seven and eight or more anti-TB drugs, the global distribution of TB strains with concurrent resistance to multiple second-line drugs had not been previously reported.

The concept and term XDR-TB as a distinct nosological entity were first developed by the Centers for Disease Control and Prevention (CDC) in March 2005 and were introduced into public use in October 2005 at the 36th World Conference on Lung Health in Paris, France [2,3]. At that meeting, data on second-line drug resistance from a joint global survey of Supranational TB Reference Laboratories conducted by the CDC and the World Health Organization (WHO), as well as treatment outcomes of XDR-TB patients in Latvia, were first presented using the working definition later published in 2006. Shortly thereafter, a cluster of TB deaths with resistance to multiple second-line drugs (called "highly drug-resistant $\mathrm{TB}^{\text {" }}$ by the scientists) in HIV-infected persons in rural KwaZuluNatal, South Africa, was presented at the 13th Conference on Retroviruses and Opportunistic Infections (Denver, CO, USA) in February 2006 [4]. At the time and for reasons that are unclear, this report did not reach the attention of the global public health community, perhaps because this new "entity" in TB control had not yet been given a new name. Shortly thereafter, the original definition for XDR-TB was first published in March 2006 [5]; it was later revised in October 2006 at an emergency meeting of the Global Task Force on XDR-TB and posted on the WHO website. The revised definition was simultaneously published in November 2006 in the Morbidity and Mortality Weekly Report [6] and in the WHO's Weekly Epidemiologic Record [7].
T.H. Holtz and J.P. Cegielski

CDC, Division of TB Elimination, Atlanta, GA, USA.

\section{STATEMENT OF INTEREST}

None declared.

\section{REFERENCES}

1 Migliori GB, Loddenkemper R, Blasi F, Raviglione MC. 125 years after Robert Koch's discovery of the tubercle bacillus: the new XDR-TB threat. Is "science" enough to tackle the epidemic? Eur Respir J 2007; 29: 423-427.

2 Shah NS, Wright A, Drobniewski F, et al. Extreme drug resistance in tuberculosis (XDR-TB): global survey of supranational reference laboratories for Mycobacterium tuberculosis with resistance to second-line drugs. Int $J$ Tuberc Lung Dis 2005; 9: Suppl. 1, S77.

3 Holtz TH, Riektsina V, Zarovska E, Laserson KF, Wells CD, Leimane V. XDR-TB: extreme drug-resistance and treatment outcome under DOTS-Plus, Latvia, 2000-2002. Int J Tuberc Lung Dis 2005; 9: Suppl. 1, S258.

4 Moll A, Gandhi NR, Pawinski R, et al. Identification of a multidrug-resistant tuberculosis cluster as a cause of death among HIV co-infected patients in rural South Africa. 13th Conference on Retroviruses and Opportunistic Infections, Denver, CO, USA. February 7, 2006, Poster O-115.

5 Centers for Disease Control and Prevention (CDC). Emergence of Mycobacterium tuberculosis with extensive resistance to second-line drugs - worldwide, 2000-2004. MMWR Morb Mortal Wkly Rep 2006; 55: 301-305.

6 Centers for Disease Control and Prevention. Notice to readers: revised definition of XDR-TB. MMWR Morb Mortal Wkly Rep 2006; 55: 1176.

7 World Health Organization. Extensively drug-resistant tuberculosis (XDR-TB): recommendations for prevention and control. Wkly Epidemiol Record 2006; 81: 430-432. 